
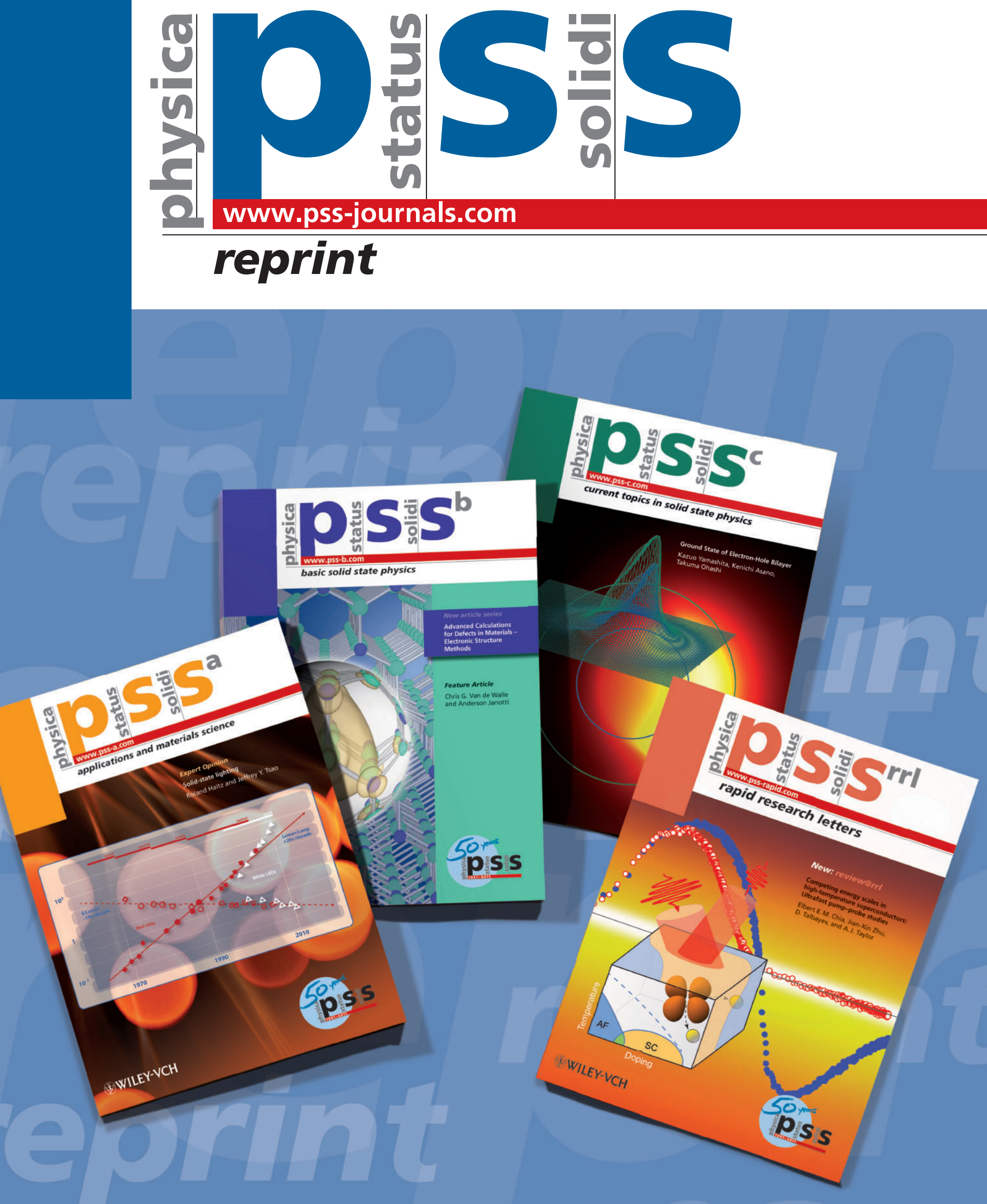


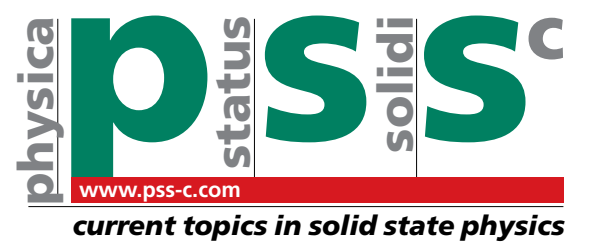

\title{
Evaluation of an InAIN/AIN/GaN HEMT with Ta-based ohmic contacts and PECVD SiN passivation
}

\author{
Anna Malmros ${ }^{*}, 1$, Piero Gamarra ${ }^{* *}, 2$ Mattias Thorsell ${ }^{1}$, Marie-Antoinette di Forte-Poisson ${ }^{2}$, \\ Cedric Lacam ${ }^{2}$, Maurice Tordjman ${ }^{2}$, Raphaël Aubry', Herbert Zirath ${ }^{1}$, and Niklas Rorsman ${ }^{1}$ \\ ${ }^{1}$ Chalmers University of Technology, Kemiv. 9, 41296 Göteborg, Sweden \\ 2 3-5 Lab/Thales Research \& Technology, Route de Nozay, 91460 Marcoussis, France
}

Received 10 July 2013, revised 20 August 2013, accepted 28 November 2013

Published online 22 January 2014

Keywords InAlN, HEMT, ohmic contact, Ta, passivation

* Corresponding author: e-mail anna.malmros@chalmers.se, Phone: +46 (0)31 772 5049, Fax: +46 (0) 31164513
** e-mail piero.gamarra@3-5lab.fr, Phone: +33 130777 148, Fax: +33 130776786

An InAIN/AIN/GaN HEMT with Au-free Ta-based ohmic contacts and a high-quality PECVD SiN passivation is reported. The ohmic contacts were annealed at $550{ }^{\circ} \mathrm{C}$, resulting in a contact resistance of $0.64 \Omega \mathrm{mm}$. The gate length was $50 \mathrm{~nm}$. The device performance and the process were evaluated by performing DC-, pulsed IV-, RF-, and load-pull measurements. It was observed that current slump was effectively mitigated by the pas- sivation layer. The DC channel current density increased by $71 \%$ to $1170 \mathrm{~mA} / \mathrm{mm}$ at the knee of the IV curve, and the transconductance increased from 382 to $477 \mathrm{mS} / \mathrm{mm}$ after passivation. At the same time the gate leakage increased, and the extrinsic $f_{\max }$ decreased from 207 to 140 GHz. Output powers of 4.1 and $3.5 \mathrm{~W} / \mathrm{mm}$ were measured after passivation at 31 and $40 \mathrm{GHz}$, respectively.
1 Introduction The AlGaN/GaN HEMT has shown to be a very promising candidate for high output power and high frequency applications. One obstacle in this technology has been reliability, partly owing to the lattice mismatch between $\mathrm{AlGaN}$ and GaN. InAlN on the other hand can be grown lattice matched to $\mathrm{GaN}$ at an In content of about $17 \%$. Commonly a thin AIN exclusion layer is used at the InAlN/GaN interface to decrease scattering caused by interface roughness and alloy disorder, thereby increasing the mobility [1]. The strong spontaneous polarization in this material implies a larger amount of electrons in the channel for a given thickness, as compared to $\mathrm{AlGaN} / \mathrm{GaN}$ heterostructures. Conversely, it can produce the same amount of electrons as a conventional $\mathrm{AlGaN} / \mathrm{GaN}$ heterostructure, but with a thinner barrier layer. Hence the material is of interest for both high-power [2] and high frequency applications.

Ohmic contacts are an essential part of a microwave transistor. Apart from a low contact resistance a smooth surface morphology is important for the detection of alignment marks and scaling of the drain/source-gate dis- tance. It has been demonstrated previously that $\mathrm{Ta} / \mathrm{Al} / \mathrm{Ta}$ metallization can produce low-resistive ohmic contacts to $\mathrm{AlGaN} / \mathrm{GaN}$ when annealed at the comparatively very low temperature of $550^{\circ} \mathrm{C}$ [3]. In this study we show that also InAIN/AIN/GaN HEMTs may be fabricated with Ta-based ohmic contacts. This resulted in a low contact resistance and a very smooth surface morphology. The devices were downscaled laterally and vertically in order to promote high-frequency performance. Measurements including DC, pulsed IV, RF, and load-pull at 31 and $40 \mathrm{GHz}$ were performed before and after deposition of the passivation layer.

2 Fabrication The InAlN/AlN/GaN heterostructure was grown by low pressure metal-organic chemical vapor deposition (MOCVD) on 3 inch SiC substrate using a close coupled multiwafer reactor. Trimethyl gallium (TMGa), trimethyl indium (TMIn), and trimethyl aluminium (TMAl) were used as group III precursors and ammonia $\left(\mathrm{NH}_{3}\right)$ as group $\mathrm{V}$ precursor. The heterostructure consisted of a $100 \mathrm{~nm}$ high temperature AlN nucleation layer, a high resistive $1.6 \mu \mathrm{m} \mathrm{GaN}$ buffer layer followed by a $2 \mathrm{~nm}$ thick 
AlN interlayer and a $6 \mathrm{~nm}$ undoped InAlN layer with $\mathrm{In}$ content of $18.8 \%$. At this In content, InAlN grown on $\mathrm{GaN}$ is nearly lattice matched. Details on the growth of nearly lattice matched InAlN/AIN/GaN HEMT structures may be found in [4].

Devices with a gate width of $2 \times 50 \mu \mathrm{m}$ and a gate length of $50 \mathrm{~nm}$ were processed. Processing started with the formation of mesas in a $\mathrm{Cl}_{2} / \mathrm{Ar}$ plasma. Ohmic contacts separated by $1 \mu \mathrm{m}$ were defined by e-beam lithography (EBL). The contact metallization consisted of a $\mathrm{Ta} / \mathrm{Al} / \mathrm{Ta}$ stack which was annealed at $550{ }^{\circ} \mathrm{C}$ in $\mathrm{N}_{2}$ ambient. Ni/Au gates, defined with EBL using a ZEP520/UV5 resist stack [5], were centered in the drain-source opening. Definition of contact electrodes was done by optical lithography followed by deposition of Ti/Au. Finally a $250 \mathrm{~nm}$ thick $\mathrm{SiN}$ passivation layer was deposited at $340{ }^{\circ} \mathrm{C}$ by PECVD.

3 Results and discussion The contact resistance was $0.64 \pm 0.03 \Omega \mathrm{mm}$ as measured with the transmission line method (TLM). The contacts exhibited a very smooth surface morphology, Fig. 1.

IV characteristics improved considerably after passivation. The channel current density increased by $71 \%$ to $1170 \mathrm{~mA} / \mathrm{mm}$ at $\left(\mathrm{V}_{\mathrm{gs}}, \mathrm{V}_{\mathrm{ds}}\right)=(1,2.4) \mathrm{V}$, Fig. 2. The maximum transconductance improved from 382 to $477 \mathrm{mS} / \mathrm{mm}$, Fig. 3. These results were consistent with Hall measurement data, showing an increase in the sheet charge density from 1.4 to $1.6 \times 10^{13} \mathrm{~cm}^{-2}$, while the mobility dropped from 1630 to $1590 \mathrm{~cm}^{2} \cdot \mathrm{V}^{-1} \cdot \mathrm{s}^{-1}$. This resulted in an overall decrease in the sheet resistance from 270 to $239 \Omega / \square$. Despite the fairly thin barrier the device suffered from short channel effects, making it hard to pinch the device at high drain voltages and causing high output conductance. This phenomenon was enhanced after passivation, likely due to the increased number of electrons in the channel.

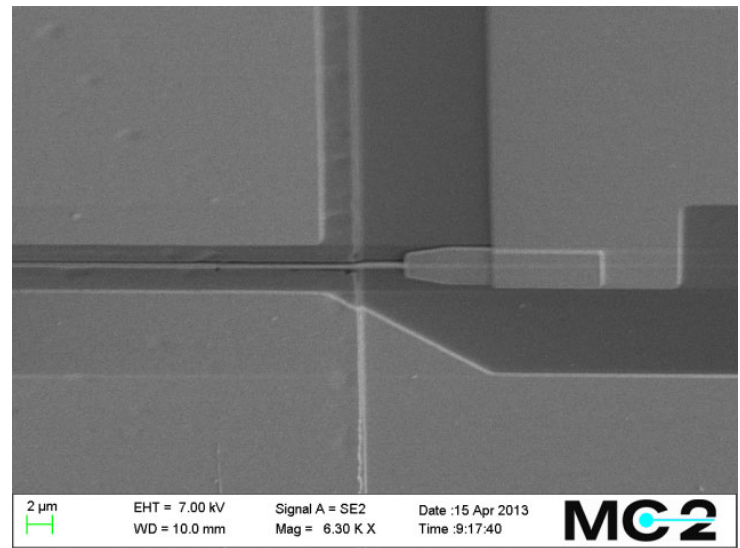

Figure 1 SEM image taken prior to passivation shows a very smooth surface morphology.

The gate leakage increased by several orders of magnitude after passivation, Fig. 4, but was still reasonably low for a GaN HEMT $(<1 \mathrm{~mA} / \mathrm{mm})$. Noteworthy, the gate leakage prior to passivation was extremely low, especially considering that InAlN/AlN/GaN HEMTs are known to have problems with gate leakage. Many groups have therefore investigated MOS HEMTs as a method of suppressing gate leakage currents [6-9]. One plausible reason for the overall low gate leakage is a native oxide at the InAlN surface. The increased gate leakage after passivation may have been due to a conductive path at the InAlN/SiN interface. It is also possible that the low gate leakage prior to passivation was a result from filled surface states near the gate, depleting the channel and thereby increasing the tunneling distance. This effect would then have been mitigated by the passivation layer.

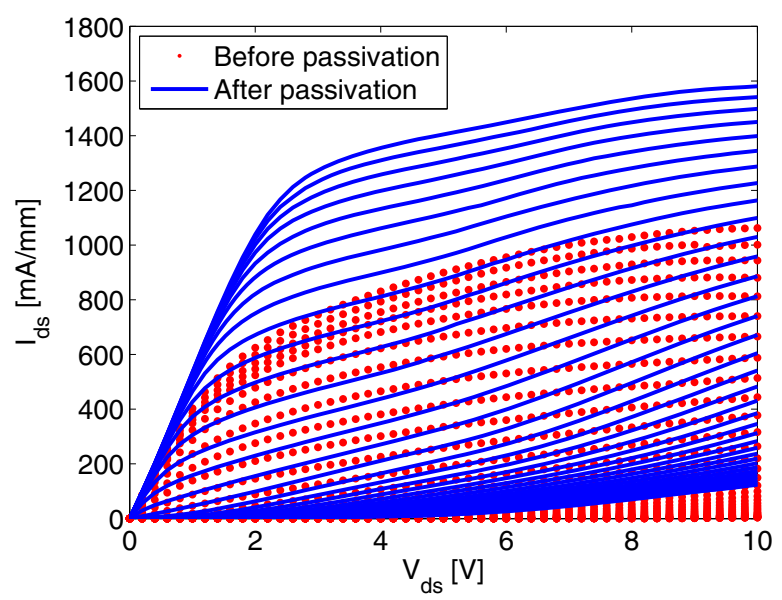

Figure $2 \mathrm{I}_{\mathrm{ds}}$ versus $\mathrm{V}_{\mathrm{ds}}$ for $\mathrm{V}_{\mathrm{gs}}$ ranging from -6 to $1 \mathrm{~V}$ with a step of $0.2 \mathrm{~V}$.

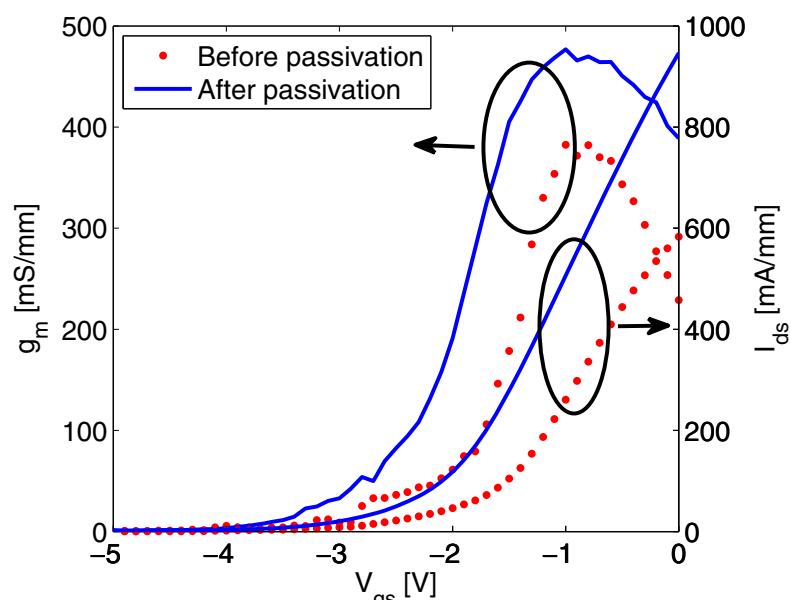

Figure $3 \mathrm{I}_{\mathrm{ds}}$ and transconductance versus $\mathrm{V}_{\mathrm{gs}}$ for $\mathrm{V}_{\mathrm{ds}}=3 \mathrm{~V}$.

The presence of filled traps in the near-gate region for a negative gate bias was confirmed by pulsed IV results. The measurements were performed by applying different quiescent bias voltages $\left(\mathrm{V}_{\mathrm{gsq}}, \mathrm{V}_{\mathrm{dsq}}\right)$ and thereafter pulsing to drain biases up to $9 \mathrm{~V}$ while the gate bias was kept cont- 


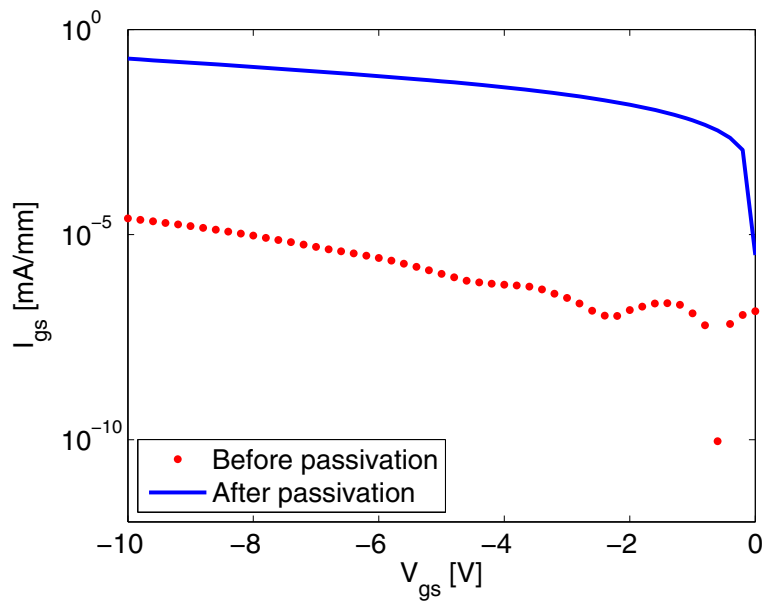

Figure 4 Gate leakage characteristics at zero drain bias.

stant a $0 \mathrm{~V}$. The pulses had a duration of $0.5 \mu$ s and were separated by $1 \mathrm{~ms}$. For the unpassivated sample a large discrepancy between the output currents $\mathrm{I}_{-10,10}$ (pulsed from $(-10,10) \mathrm{V}$ ) and $\mathrm{I}_{0,0}$ (pulsed from $(0,0) \mathrm{V}$ ) was observed, Fig. 5. This is an indication of lag effects, caused by trapped electrons at the surface and/or in the bulk. Both the on-resistance and the current in the saturated region were improved after passivation. This suggests that the majority of the electrons causing dispersive behaviour were trapped at the surface. The slump ratio, defined as $\mathrm{I}_{-10,10} / \mathrm{I}_{0,0}$ pulsed at $\mathrm{V}_{\mathrm{ds}}=3 \mathrm{~V}$ improved from $12 \%$ to $78 \%$.

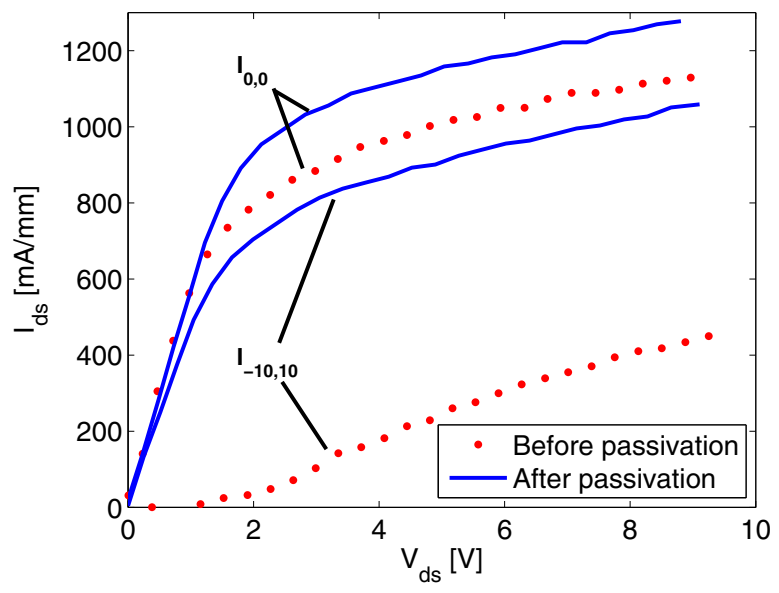

Figure 5 Pulsed IV characteristics at two different quiescent bias points.

RF measurements were performed in the 0.1 to $110 \mathrm{GHz}$ range. Prior to passivation the extrinsic values of $f_{T}$ and $\mathrm{f}_{\max }$ were 90 and $207 \mathrm{GHz}$, respectively, Fig. 6a. These values were obtained by extrapolation at $-20 \mathrm{~dB} /$ decade. $\mathrm{f}_{\max }$ decreased considerably after passivation to $140 \mathrm{GHz}$, whereas $f_{T}$ remained unchanged, Fig. $6 b$. The drop in $f_{\max }$ was associated with the increase in output conductance after passivation.

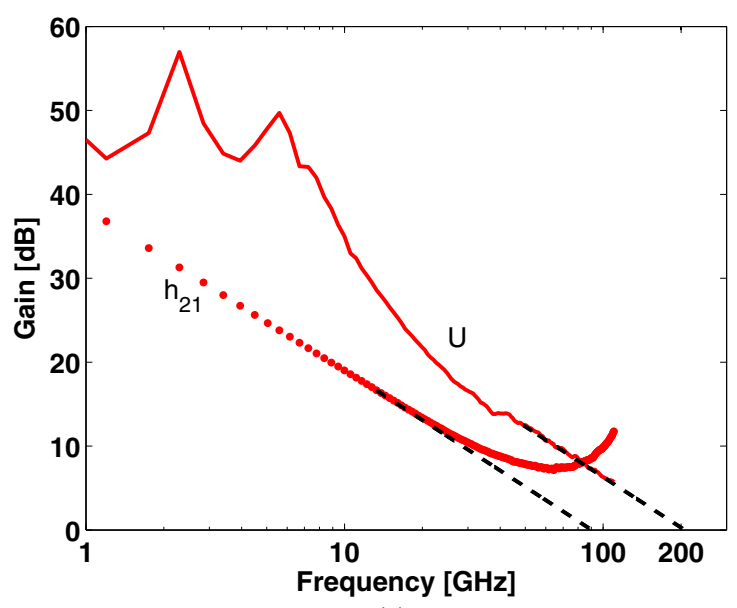

(a)

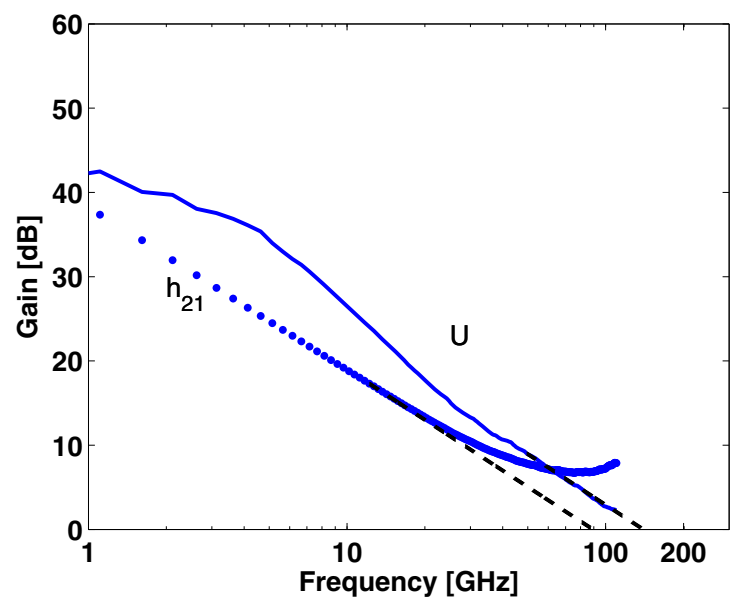

(b)

Figure 6 RF characteristics, a) before passivation and b) after passivation.

InAlN/AlN/GaN HEMTs have previously shown to deliver output powers up to $5.8 \mathrm{~W} / \mathrm{mm}$ at $35 \mathrm{GHz}$ [10]. In this study CW load-pull measurements were performed using a Maury system with tunable source- and load impedances. The output power was measured at $3 \mathrm{~dB}$ gain compression, or at the maximum available input power if the 3 $\mathrm{dB}$ compression point was not reached. The maximum available input power was limited to $35 \mathrm{dBm}$ minus the losses in the setup and reflections the inputs of the tuners.

At $31 \mathrm{GHz}$ the passivated HEMT delivered a maximum output power of $4.1 \mathrm{~W} / \mathrm{mm}$ and a drain efficiency of 27\%, Fig. 7. The unpassivated HEMT delivered $1.7 \mathrm{~W} / \mathrm{mm}$ and a drain efficiency of $19 \%$ at the same frequency. At 40 $\mathrm{GHz}$ the passivated and unpassivated HEMT exhibited output powers of 3.5 and $1.5 \mathrm{~W} / \mathrm{mm}$ and drain efficiencies of 21 and $16 \%$, respectively. The output power scaled with the drain bias in class A operation, Fig. 8. 


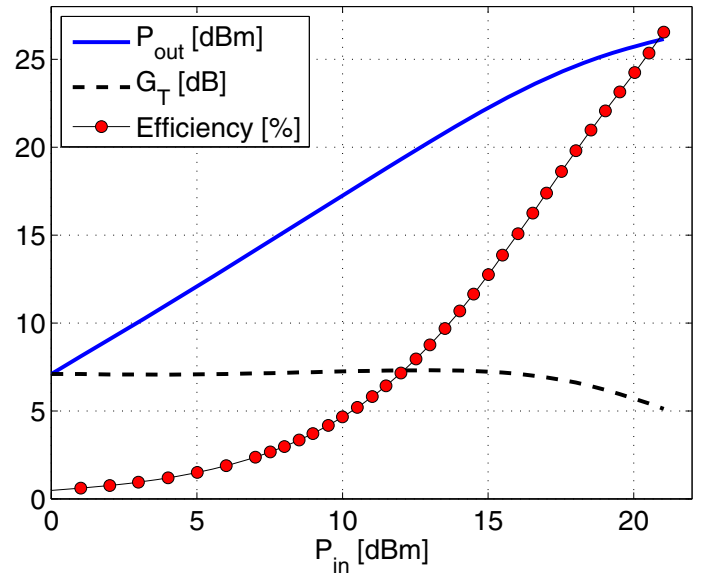

Figure 7 Results from load-pull measurements on the passivated HEMT at $31 \mathrm{GHz}$ at $\mathrm{V}_{\mathrm{ds}}=20 \mathrm{~V}$ and $\mathrm{V}_{\mathrm{gs}}=-2.5 \mathrm{~V}$.

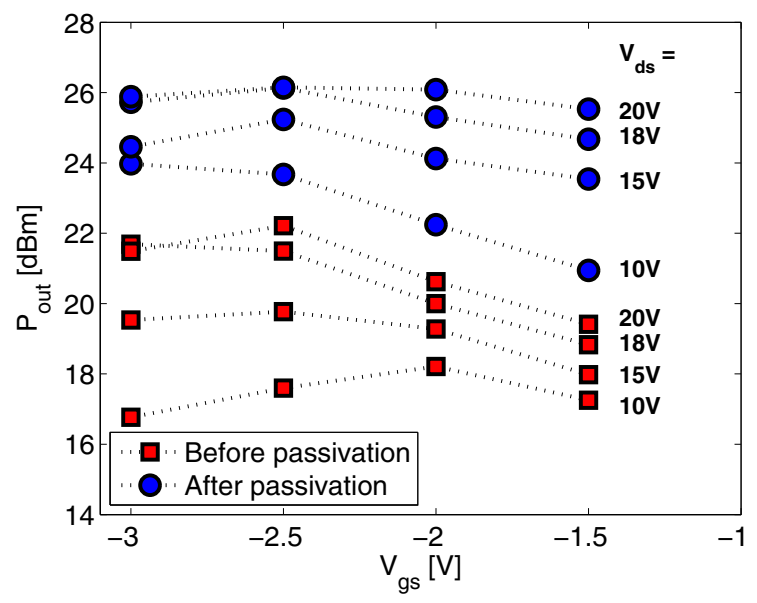

Figure 8 Output power versus bias at $31 \mathrm{GHz}$ before and after passivation.

4 Conclusion An InAlN/AlN/GaN HEMT with Tabased ohmic contacts and SiN passivation deposited by PECVD was demonstrated. The ohmic contact process yielded a contact resistance of $0.64 \Omega \mathrm{mm}$ and a very smooth contact surface. The passivation layer effectively decreased lag effects and increased the amount of electrons in the channel. Consequently the output power increased; the maximum output power at $31 \mathrm{GHz}$ was $4.1 \mathrm{~W} / \mathrm{mm}$. On the negative side the gate current increased and a considerable reduction of $f_{\max }$ was observed. Nevertheless the passivated device exhibited an extrinsic $f_{T}$ and $f_{\max }$ of 90 and $140 \mathrm{GHz}$, respectively.

Acknowledgements This research was carried out within the MANGA project and was partly financed by the Swedish Foundation for Strategic Research (SSF) and the Swedish Research Council (VR).

\section{References}

[1] P. Gamarra, C. Lacam, M. Magis, M. Tordjman, and M.-A. di Forte-Poisson, Phys. Status Solidi A 209, 21 (2012).

[2] N. Sarazin, E. Morvan, M. A. di Forte-Poisson, M. Oualli, C. Gaquière, O. Jardel, O. Drisse, M. Tordjman, M. Magis, and S. L. Delage, IEEE Electron Device Lett. 31, 11 (2010).

[3] A. Malmros, H. Blanck, and N. Rorsman, Semicond. Sci. Technol. 26, 075006 (2011).

[4] M. A. di Forte-Poisson, N. Sarazin, M. Magis, M. Tordjman, J. Di Persio, R. Langer, E. Iliopoulos, A. Georgakilas, P. Kominou, M. Guziewicz, E. Kaminska, A. Piotrowska, C. Gaquière, M. Oualli, E. Chartier, E. Morvan, and S. Delage, Phys. Status Solidi C 7, 1317 (2010).

[5] L. E. Ocola, D. M. Tennant, and P.D. Ye, Microelectron. Eng. 67-68, 104 (2003).

[6] M. Alomari, A. Chuvilin, L. Toth, B. Pecz, J.-F. Carlin, N. Grandjean, C. Gaquière, M.-A. di Forte-Poisson, S. Delage, and E. Kohn, Phys. Status Solidi C 7, 13 (2010).

[7] D. S. Lee, J. W. Chung, H. Wang, X. Gao, S. Guo, P. Fay, and T. Palacios, Electron Device Lett. 32, 755 (2011).

[8] D. S. Lee, X. Gao, S. Guo, D. Kopp, P. Fay, and T. Palacios, IEEE Electron Device Lett. 32, 1525 (2011).

[9] J. Kuzmik, G. Pozzovivo, S. Abermann, J.-F. Carlin, M. Gonschorek, E. Feltin, N. Grandjean, E. Bertagnolli, G. Strasser, and D. Pogany, IEEE Trans. Electron Devices 55, 937 (2008).

[10] A. Crespo, M. M. Bellot, K. D. Chabak, J. K. Gillespie, G. H. Jessen, V. Miller, M. Trejo, G. D. Via, D. E. Walker, B. W. Winningham, H. E. Smith, T. A. Cooper, X. Gao, and S. Guo, IEEE Electron Device Lett. 31, 2 (2010). 